\section{Andamios Revista de Investifación Social}

Andamios. Revista de Investigación

Social

ISSN: 1870-0063

revistaandamios@uacm.edu.mx

Universidad Autónoma de la Ciudad de

México

México

Hernández Vicencio, Tania

El Partido Acción Nacional en la lucha por la no despenalización del aborto en el Distrito Federal Andamios. Revista de Investigación Social, vol. 8, núm. 15, enero-abril, 2011, pp. 367-396 Universidad Autónoma de la Ciudad de México

Distrito Federal, México

Disponible en: http://www.redalyc.org/articulo.oa?id=62819892015

- Cómo citar el artículo

- Número completo

- Más información del artículo

- Página de la revista en redalyc.org

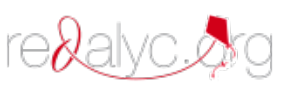

Sistema de Información Científica

Red de Revistas Científicas de América Latina, el Caribe, España y Portugal

Proyecto académico sin fines de lucro, desarrollado bajo la iniciativa de acceso abierto 


\title{
El Partido Acción Nacional en la lucha por la nO DESPENALIZACIÓN DEL ABORTO EN EL Distrito Federal
}

Tania Hernández Vicencio*

\begin{abstract}
ResUMEN: Este trabajo tiene como objetivo analizar la postura que asumió el Partido Acción Nacional (PAN) en la lucha por la no despenalización del aborto en el Distrito Federal. Como parte de una amplia red de actores sociales que se manifestaron en contra de la aprobación de las más recientes reformas en esta materia, tanto los panistas del gobierno federal, como los legisladores y dirigentes del PAN en la ciudad de México seinvolucraron en una disputa pública defendiendo una errónea concepción sobre la laicidad del Estado mexicano. Con su postura, Acción Nacional simplificó la problemática en torno al aborto sobre la base de tesis moralizantes y fungió como el catalizador de una nueva embestida de los católicos conservadores contra el Estado laico.

Palabras clave: Pan, católicos conservadores, laicidad, despenalización, aborto.
\end{abstract}

INTRODUCCIÓN

El 24 de abril de 2007 en el Distrito Federal se aprobaron varias reformas a la Ley de Salud y al Código Penal, con el fin de despenalizar el aborto durante las primeras doce semanas de embarazo. ${ }^{1}$ El antecedente

\footnotetext{
* Doctora en Ciencias Sociales por El Colegio de la Frontera Norte. Profesora-investigadora de la Dirección deEstudios Históricos del Instituto Nacional de Antropología e H istoria (INAH).Correo electrónico: thernandez.deh@inah.gob.mx

${ }^{1}$ Se considera que en la capital del país el aborto representa la tercera causa de muerte materna, mientras que a nivel nacional es la quinta cau sa de muerte de las mujeres en edad reproductiva. De acuerdo con datos publicados por Juárez, Singh, García y Díaz (2008), en 2006 la Ciudad de M éxico reportó una tasa de aborto de 34 por cada 1000 mujeres en edad reproductiva, es decir, un porcentaje ligeramente más alto que el de la República mexicana que es de 33 por cada 1000.
}

Volumen 8, número 15, enero-abril, 2011, pp. 367-396 
inmediato de esta reforma era la denominada Ley Robles, aprobada el 18 de agosto de 2000, como resultado de la fuerte movilización que llevaron a cabo los grupos feministas para presionar al gobierno de la capital del país a fin de que éste promoviera modificaciones sustanciales a la ley en materia de aborto. ${ }^{2}$ Durante ese proceso, el Partido Acción Nacional (PAN) manifestó su rotunda oposición a los cambios en la normatividad, por lo que el 25 de septiembre de 2000, diecisiete diputados panistas y cinco del Partido Verde Ecologista de México (PVEM), interpusieron una acción de inconstitucionalidad ante la Suprema Corte de Justicia de la Nación (SCJN) contra las reformas aprobadas. Casi un año y medio después, en una votación de siete a cuatro, la SCJN resolvió que no existía inconstitucionalidad. ${ }^{3}$

Con el fin de aportar elementos de análisis sobre el papel que ha jugado el PAN, como partido en el gobierno, en la lucha por la no despenalización del aborto, en este trabajo se discute su actuación en el marco del más reciente debate realizado en 2007. Al respecto, planteo que, desde el principal espacio de poder nacional, el PAN se ha erigido en el catalizador de lo que es una nueva embestida de los sectores conservadores de la sociedad contra el Estado laico; por lo que ha pretendido simplificar la problemática en torno al aborto sobre la base de tesis moralizantes y ha violentado el orden constitucional al pasar por alto el contenido del artículo 130 de la Constitución. El panismo inició el nuevo siglo reposicionando a la Iglesia católica en el debate y la lucha política, y pretendió hacer de la moral cristiana conservadora la esencia de la política pública. A través del debate sobreel aborto, Acción Nacional mostró la cara de un partido cargado más que nunca hacia el conservadurismo, con una visión retrógrada sobre el tema del aborto y en franca confrontación con el Estado liberal.

\footnotetext{
${ }^{2}$ De acuerdo con Martha Lamas, después del triunfo panista en las elecciones presidenciales del año 2000, dos situaciones pusieron en alerta al movimiento feminista. El caso de violación de la adolescente conocida como Paulina, a quien el gobierno de Baja California no le permitió abortar; y, en Guanajuato, el intento del PAN en el Congreso local de eliminar el aborto por violación (Lamas, 2009: 162-164).

${ }^{3}$ Con la Ley Robles se incluyeron en la ley las siguientes modificaciones: de peligro de muerte se reconoció el grave riesgo a la salud de la mujer; se autorizó el aborto por malformaciones del feto, y se planteó la invalidez de un embarazo por inseminación artificial no consentida (Lamas, 2009: 161 y 165).
} 


\section{EL INICIO DE LA CONTROVERSIA Y LOS PRIMEROS ENFRENTAMIENTOS}

La pugna en torno al aborto en el Distrito Federal resurgió con vigor cuando el 26 de noviembre de 2006, el diputado Armando Tonatiuh González, del Partido Revolucionario Institucional (PRI), presentó una propuesta para modificar los artículos 145, 146, 147 y 148 del capítulo $\checkmark$, relativo al aborto, del Código Penal del Distrito Federal; y los artículos 14, 14bis 1, 14bis 2, 14bis 3, 14bis 4, 14bis 5 y 14bis 6, del capítulo II, de la Ley de Salud de la capital del país. A partir de ese momento, en la Asamblea Legislativa del Distrito Federal (ALDF) circularon varios proyectos de dictamen en torno al tema y se fue generando una fuerte controversia que alcanzó proporciones nacionales e internacionales.

Desde el inicio de 2007 los grupos católicos conservadores ${ }^{5}$ se manifestaron en contra de la propuesta para modificar la ley sobre el aborto. El 25 de marzo la Arquidiócesis de la I glesia católica, la Unión Nacional de Padres de Familia (UNPF) y la organización Somos Vida llevaron a cabo la primera peregrinación a la Basílica de Guadalupe ${ }^{6}$ movilización a la que se sumaron algunos grupos protestantes e incluso miembros del ejército mexicano (González, 2007), mostrando su rechazo a un nuevo cambio de la ley que avanzara haciala despenalización del aborto. Expresiones de fuerza como ésta, que durante muchos años fueron impensables en el marco del proceso de secularización de la sociedad y las instituciones mexicanas, a partir de entonces habrían de convertirse

\footnotetext{
${ }^{4}$ Según datos de la encuesta levantada por la empresa Parametría en la capital del país entreel 24 y 27 de marzo de 2007, 76\% de los habitantes dela Ciudad de México y 83\% de los del resto del país manifestaba tener conocimiento de la discusión en torno al aborto. Véase Parametría (2007).

${ }^{5}$ Este sector de la sociedad basa su concepción de la ley en una visión iusnaturalista y considera que la religión católica es un elemento central de la identidad nacional. Para los católicos conservadores el derecho natural - cuyo origen está cifrado en la voluntad de Dios- siempre estará por encima de los argumentos científicos y de la ley producida por los hombres y las instituciones. Las normas convencionales del derecho se asientan en principios universales einmutables que conforman el derecho natural, el cual es prerrogativa detodas las personas desde el momento de su nacimiento y la sociedad deberá organizarse jurídicamente para protegerlo.

${ }^{6}$ La manifestación se desarrolló en el marco del III Congreso Internacional Provida, cel ebrado en la Ciudad de México del 23 al 25 de marzo de 2007.
} 
en una expresión fundamental de las demandas de un nutrido sector de los católicos. Por años se pensó equivocadamente que lo religioso no tenía una manifestación social; sin embargo, en M éxico las manifestaciones públicas de los creyentes obtu vieron su carta de naturalización a partir del reconocimiento jurídico de las asociaciones religiosas, el cual quedó plasmado en las modificaciones constitucionales de 1992, que otorgaron el reconocimiento jurídico a las iglesias, y le concedieron importancia a su papel social, y al de otras formas de expresión comunitaria de lo religioso en la vida nacional (Blancarte, 2004: 5).

Cierto es que el ámbito de la política y el de la religión tienen sus propias reglas internas, pero en distintos momentos de la historia reciente del país las fronteras entre ambos espacios han tendido a desdibujarse. Es importante señalar, empero, que el reconocimiento de que los límites entre ambas estructuras en ocasiones pueden ser difusos, y de que es probable que algunos actores políticos intenten trasladar sus convicciones personales - en particular la religiosa - a la agenda pública, no significa la aceptación de que esto es permisible (Blancarte, 2004: 5). En un contexto social y político altamente complejo como el que hoy tenemos en México, se hace necesario insistir con claridad en la separación entre el espacio público y el privado, entre la política y la religión, sobre todo cuando existe una gran ofensiva de algunas religiones, organizaciones y grupos conservadores contra el Estado laico. A la par del proceso de transformación de la sociedad mexicana que, entre otras cosas, ha significado una mayor tolerancia a la manifestación pública de la diversidad, hay que decir que cada vez hay más mexicanos de acuerdo con la separación de las creencias religiosas de la toma de decisiones en la esfera pública y en contra de que los legisladores voten las leyes de acuerdo con los principios de la religión que profesan. Es decir, legalmente no está prohibido que los funcionarios sean creyentes e incluso practicantes de las ceremonias propias de su religión, pero sí existe un rechazo manifiesto a que sus convicciones personales en materia religiosa se trasladen al ámbito de la función pública.

La siguiente acción de la jerarquía de la Iglesia católica fue el pronunciamiento del cardenal Norberto Rivera Carrera, quien desde el púlpito acusó a los legisladores de "mantener un embate implacable en contra de los valores de la familia, al haber aprobado una ley inmoral 
denominada de convivencia", ${ }^{7}$ y luego insistió: "en una ley inicua que pretende hacer legal lo que de suyo es inmoral: la eliminación del niño en el vientre de su madre" (Martínez et. al., 2007). La Arquidiócesis Primada de México (APM), encabezada por el cardenal Rivera, fijó la postura de los obispos mexicanos a partir de un documento que fue elaborado en 1999 y cuyo contenido se recuperó en esta ocasión, haciendo un llamado a los católicos a "no votar por las fuerzas políticas que no respetan ni defienden la vida". Con ese llamado una diversidad de agrupaciones de la sociedad civil de ideología conservadora volvió a volcarse a la calle, bajo la coordinación del Colegio de Abogados Católicos (CAC) que encabeza Armando Martínez, quien se expresó en los siguientes términos: "Vamos a movilizar a los católicos y a todas las religiones y saldremos a la calle a defender la vida [...] no a favor de la cultura de la muerte que se quiere hacer ahora [... ] si no lo han entendido con la negociación política, esperemos hacerlos entender en la calle" (Flores, 2007b). El activismo político de la élite de la Iglesia católica fue más que solapada por la Secretaría de Gobernación (SEGOB) y la Presidencia de la República al dejar abierta la posibilidad de que los dirigentes católicos confrontaran el orden constitucional, violando el inciso "e" del artículo 130, que niega a los ministros de culto la posibilidad de "[... ] oponerse a las leyes del país o a sus instituciones, ya sea en reunión pública, en eventos de culto, de propaganda religiosa o en publicaciones de carácter religioso". La jerarquía católica mostró su confianza de no ser sancionada por las autoridades y continuó haciendo un Ilamado a su feligresía para que saliera a las calles, además de publicar severas críticas en varios de sus órganos informativos.

A la reacción de los grupos conservadores de la I glesia se sumó la activa participación de varios integrantes de primer nivel del gobierno federal de filiación panista, mientras que el presidente de la República, Felipe Calderón, se limitó a decir que él estaba "a favor de la vida". Por su parte, Margarita Zavala, titular del Sistema Nacional para el DesarroIlo Integral de la Familia (DIF) y esposa del presidente, inició una fuerte

\footnotetext{
${ }^{7}$ Un elemento que recrudeció la confrontación entre los grupos promotores y los opositores a la despenalización del aborto, fuela aprobación dela Ley de Asociaciones de Convivencia, que entró en vigor el 16 de marzo de 2007, y la cual permite la unión entre personas del mismo sexo.
} 
campaña en todo el país promoviendo la idea de que era necesario "defender la vida desde el nacimiento hasta la muerte natural" y propuso, como medida para evitar que las mujeres llegasen a abortar, la instrumentación de un programa de educación sexual encabezado por el DIF.

Además, el entonces titular de la Segob, Francisco Ramírez Acuña, lanzó la idea de establecer una mesa de diálogo entre los legisladores y la jerarquía eclesiástica, con el fin de que cambiaran impresiones en torno a la propuesta de reforma, reunión para la cual la se ofrecía como mediadora a la propia Secretaría. Q uien era dirigente nacional del PAN, Manuel Espino Barrientos, afirmó: "Ratificamos nuestra mentalidad en torno a la persona, objetivo supremo de nuestra acción, a la que reconocemos como tal desde el momento de su concepción hasta la muerte natural. Por ello, se solicita respetuosamente a los gobiernos emanados de Acción Nacional y a todos sus grupos parlamentarios que promuevan programas de salud reproductiva, que respeten la dignidad humana" (Hernández, 2007). En este mismo tenor, el ex secretario de Gobernación, Carlos Abascal Carranza, ${ }^{8}$ y entonces secretario adjunto del blanquiazul planteó: "EI PAN dará la pelea para que la Asamblea Legislativa del Distrito Federal no apruebe la nueva ley que permitirá el aborto [... ] vamos a pelear en el terreno del partido con argumentos propios [para] evitar que se dicte una ley de sangre en donde se legalice el asesinato de personas [... ]. Son enormes los daños psicológicos y hormonales que sufre la mujer con motivo del aborto" (Flores, 2007a).

Para la segunda semana de abril de 2007, la Conferencia del Episcopado Mexicano (CEM) se expresó públicamente exhortando a los partidos políticos, en particular al Partido de la Revolución Democrática (PRD) - que se había convertido en el promotor más activo de la reforma - a "tener prudencia en la aprobación de normas que lastiman la sensibilidad de la sociedad", y a "construir desde las coincidencias". Mientras tanto, la Arquidiócesis insistía en descalificar la iniciativa calificándola de "hitleriana y nazi", pues en su opinión pretendía "eliminar la vida dentro del vientre de la madreúnicamente por considerarlo

${ }^{8}$ En 2005, cuando Abascal fungía como secretario de Gobernación intentó - sin éxitodetener la inclusión de la píldora anticonceptiva de emergencia en el cuadro básico de salud. 
un estorbo" (EsMas.com, 2007). Por otro lado, aunque los obispos de la CEM publicaron un documento en el que afirmaron que la discusión tenía que ver con la defensa de los derechos humanos, no se referían precisamente a los derechos de la mujer, sino más bien a los derechos humanos del neonato (Balboa, 2007a). Para ellos la solución al problema de los embarazos no deseados consistía en dar a la juventud una mejor educación sexual, basada, por supuesto, en los principios de la moral católica conservadora.

\section{EL ACOTAMIENTO DE LA PROPUESTA Y UNA NUEVA OLA DE REACCIONES}

Los diputados panistas funcionaron como catal izadores de las demandas de los grupos católicos conservadores en la ALDF. Ahí tuvieron que hacer frente a una fuerte al ianza progresista integrada por los legisladores del PRD, algunos diputados prí́stas, y los representantes del Partido Nueva Alianza y de la Coalición Socialdemócrata, esta última integrada por miembros del Partido Alternativa Social Demócrata y Campesina, el Partido del Trabajo y Convergencia. De manera que cuando los panistas propusieron que se realizara un referéndum para que la sociedad capitalina decidiera si estaba a favor o en contra de despenalizar el aborto, su planteamiento no prosperó; el 17 de abril, el pleno de la Asamblea negó la posibilidad de que este ejercicio se llevara a cabo (Llanos y Romero, 2007). ${ }^{9}$ Fue entonces cuando el dirigente del Comité Nacional Provida, ${ }^{10}$ Jorge Serrano Limón, demandó al presidente de la República ser contundente - literalmente a "fajarse los pantalones"-

\footnotetext{
${ }^{9}$ El referéndum no se realizó a pesar de que Armando Martínez, presidente del CAC, aseguró haber reunido las 36 mil firmas, equivalenteal $0.5 \%$ sobre el número de habitantes empadronados en el Distrito Federal, que eran requeridas por el Instituto Electoral del Distrito Federal para que se justificara la realización de un referéndum sobre la despenalización del aborto.

10 En México, el Comité Nacional Provida nació como asociación civil en 1978 precisamente en respuesta a una iniciativa de ley enviada por el Partido Comunista a la Cámara de Diputados para legalizar el aborto en M éxico. Durante los años ochenta esta organización comenzó a participar activamente en el marco de al gunas campañas electorales de candidatos panistas, quienes también eran miembros de Provida.
} 
en relación con el tema del aborto, ya que su antecesor, el panista Vicente Fox, tampoco había defendido la vida (Llanos, 2007).

Por su parte, Rodrigo Aguilar y J onás Guerrero, obispos de Tehuacán y Auxiliar de la Ciudad de M éxico, respectivamente, manifestaron antes que cualquier otro grupo, que la Iglesia católica no descartaba la posibilidad de interponer una controversia constitucional ante la SCJN si la ley era aprobada. También amenazaron diciendo que por medio de sus regiones pastorales, diócesis y parroquias, Ia I glesia católica buscaría impugnar la decisión de la ALDF, para que, en caso de aprobarse, la ley no se generalizara a todo el país.

Más allá de los amagos de las organizaciones civiles como Provida y de la jerarquía de la Iglesia católica, hay que enfatizar el desconocimiento o la indiferencia que los diputados y funcionarios panistas mostraron ante el reconocimiento de los "derechos reproductivos" que ya está consagrado en el artículo 4으 de la Constitución. El contenido de este precepto no sólo observa el derecho de toda persona a decidir sobre cómo reproducirse, lo que queda estipulado como: "de manera libre, informada y responsable", sino también hace referencia a la decisión de si reproducirse o no, por lo que se estipula el derecho a decidir "sobre el número y el espaciamiento de sus hijos". También quedó en evidencia la ignorancia de los funcionarios panistas respecto a los convenios internacionales que el gobierno de México ha suscrito en materia de derechos humanos, y en los que particularmente se ha mostrando acuerdo con los organismos internacionales, en el sentido de que debe asegurarse una atención médica de calidad para las mujeres, lo que involucra a los servicios de salud relacionados con la suspensión del embarazo.

Los razonamientos esgrimidos por los grupos conservadores (entre los que se encontraba un buen número de panistas) pueden resumirse de la siguiente forma: a) oponerse a la ley para despenalizar el aborto es estar a favor de la vida, apoyarla es estar a favor de la muerte; b) impulsar la reforma significa promover el aborto; c) quien aborta 0 ayuda a practicar un aborto es un asesino; d) la despenalización del aborto no puede ser decidida por los legisladores, sino por la mayoría de los mexicanos, y esa mayoría - que profesa la religión católica- 
debe seguir la postura de su I glesia; e) la Constitución mexicana defiende la vida desde el momento de la concepción hasta la muerte natural.

Estos razonamientos, entre otras cosas, denotaban una errónea concepción respecto a la laicidad del Estado y un nuevo intento de los grupos conservadores para transitar de lo que ha sido un laicismo excluyente, en el que es mal vista cualquier manifestación de lo religioso en la vida pública (Puente, 2002), ${ }^{11}$ a un Estado de rasgos confesionales. Durante la disputa por la despenalización del aborto, los opositores a las reformas argumentaron que el principio de laicidad ha sido malamente utilizado para justificar la existencia de un Estado ateo y particularmente persecutorio de los derechos de los católicos. En su opinión, a lo largo de los años el Estado mexicano desvirtuó la esencia de la laicidad, la cual, en su opinión, implica esencialmente garantizar la plena libertad religiosa, pero de una libertad que es entendida como la posibilidad de que las instancias religiosas y las feligresías encuentren como único límite a su actuación las reglas internas de sus propias iglesias.

En México, el principio de laicidad se estableció en las leyes de Reforma (1859-1860), pero fue con la redacción del artículo 130 de la Constitución de 1917 que se fortaleció la separación entre el poder político y el religioso. ${ }^{12} \mathrm{~A}$ partir de entonces, algunos sectores de la sociedad que abrevan del conservadurismo del siglo XIX se han opuesto sistemáticamente al contenido de ciertos artículos de la Carta Magna (como el 30 y el 130), por considerarlo excluyente de los derechos de los católicos. Durante el siglo XX, sin embargo, el laicismo excluyente, operó con claridad durante el gobierno de Plutarco Elías Calles (19241928), de tintes abiertamente anticlericales, y los primeros años de la

${ }^{11}$ El laicismo no es sinónimo de laicidad. El primero hace alusión a un movimiento ideológico que, si bien en un principio no rechaza a la religión, sí niega la sumisión directa o indirecta de lo político a lo religioso, por lo que puede llegar a manifestarse como la oposición total a la expresión religiosa.

${ }^{12}$ Heredero de la tradición francesa, el principio de laicidad del Estado mexicano se expresó en cuatro pilares: la búsqueda de la separación total del Estado y la I glesia católica; en la privatización dela religión; en la construcción de una escuela pública laica con exclusión de la enseñanza religiosa, y en un intento por apuntalar a la moral laica como fundamento dela vida pública. 
administración de Lázaro Cárdenas (1934-1940), cuando se aplicaron a pie juntillas varios de los artículos que generaban controversia con la jerarquía eclesiástica. La I glesia católica y el Estado mexicano más bien evolucionaron en el marco del llamado modus vivendi, nombre que se le dio al periodo de tolerancia que caracterizó a la actitud que mantuvo el gobierno respecto a la Iglesia, y que - si bien inició formalmente con los pactos de paz de 1929, tras la guerra cristera- en los hechos comprende los años de 1938 al final de los años cincuenta. Esa relación se fue modificando poco a poco a partir de la década de 1960, cuando la Iglesia católica logró alcanzar una mayor autonomía sobre el poder político, y fue al inicio de los años noventa cuando dicha autonomía incluso llegó a ser promovida por el entonces presidente de la República, Carlos Salinas de Gortari, como parte de la construcción de una gran alianza con distintos actores de derecha. Irónico fue observar cómo mientras importantes sectores sociales de la Ciudad de México demandaban respeto al principio de laicidad del Estado, los panistas insistían en defender una visión retrógrada sobre el tema en el contexto de una sociedad más plural y abierta, y en encabezar una actitud revanchista frente al Estado, ahora desde el poder.

Por otro lado, el panismo olvidó que el asunto de la laicidad, no sólo alude a la autonomía de las instituciones públicas, sino también a la laicidad de la sociedad (Scola, 2007), respecto del magisterio eclesiástico y de las organizaciones confesionales. Acción Nacional pasó por al to que el desarrollo social tarde o temprano terminará por incidir en el contenido de las leyes que establecen lo que es aceptable para la convivencia, y que si una sociedad cambia, pero las leyes no reflejan ese cambio, el orden social corre el riesgo de caer en un serio conflicto (Sartori, 2003). Según la Encuesta Nacional de Cultura Política y Valores Ciudadanos realizada en México en 2005, 76\% de los encuestados estaba en desacuerdo con la idea de que los sacerdotes o ministros religiosos participasen en la vida política. Si bien esta pregunta no fue incluida en el cuestionario aplicado en 2008, por lo que no es posible hacer una comparación con la situación actual, es importante destacar que en relación con el debate sobre el aborto, el porcentaje de mexicanos que hoy se manifiesta en desacuerdo con que el gobierno intervenga en la decisión de abortar deuna mujer aumentó siete puntos en relación 
con 2005, en ese entonces el porcentaje fue de $55 \%$ y en 2008 de $62 \%$. Además, en una encuesta levantada en 2007 por Parametría se establecía que $65 \%$ de la población del país se manifestaba de acuerdo con el aborto al peligrar la vida de la madre; 59\% lo acepta en caso de violación; $58 \%$ lo veía bien cuando existiesen malformaciones del feto; 19\% creía que debía practicarse cuando hubiese escasez de recursos y sólo $18 \%$ lo aceptaba cuando los proyectos de vida y desarrollo de la mujer se vieran afectados. Mientras que en el Distrito Federal estos porcentajes eran mayores: $74 \%$ de la población se manifestaba de acuerdo con el aborto en caso de violación; 73\% lo aceptaba en caso de que peligrara la vida de la madre; $71 \%$ estaba de acuerdo en que se practicara en caso de malformaciones del feto; $37 \%$ creía que se trataba de una medida adecuada en caso de escasez de recursos, y 35\% lo aceptaba en caso de que el proyecto de vida y desarrollo de la mujer se vieran afectados (Parametría, 2007).

Para avanzar en la discusión y hacer contrapeso a los grupos de católicos, varios diputados consideraron necesario incluir en el debate una reflexión sobre la concepción misma de aborto. El 19 de abril de 2007 las Comisiones Unidas de Equidad, Justicia y Salud de la ALDF, los diez legisladores del PRD, uno del PRI, dos de la Coalición Social demócrata y uno de N ueva Alianza, acordaron proponer una nueva concepción sobre el aborto que habría de incluirse en el artículo 144 del Código Penal. En la nueva redacción se estableció que "aborto es la interrupción del embarazo después de la décima segunda semana degestación" y se propuso la reducción de la pena para aquellas mujeres que recurrieran a la suspensión del embarazo después de ese periodo, por lo que se planteó que la sanción pasara de ser de 1 a 3 años de prisión, a una pena de 3 a 6 meses de cárcel o de 100 a 300 días de trabajo comunitario.

El dictamen aprobado en comisiones, también incluyó la figura de "aborto forzado", con la que se hacía alusión a la interrupción del embarazo sin el consentimiento de la mujer. En ese sentido se estableció que "al que hiciere abortar a una mujer por cualquier medio, sin su autorización, se le impondrá una pena de 5 a 8 años de prisión; si mediara violencia física o moral, se impondrá la pena de 8 a 10 años de prisión", y en ambos casos será considerado un delito grave, sin derecho 
a libertad bajo caución. Además se precisó que si el aborto forzado fuese provocado por un médico cirujano o partera, enfermero o practicante, a éste se le suspendería del ejercicio de su profesión u oficio por el periodo correspondiente a la pena de prisión. En cuanto a la Ley de Salud, se definió que el gobierno del Distrito Federal, a través de sus instituciones públicas de salud, tendría la obligación de atender a las mujeres que solicitaran abortar, aun cuando éstas contaran con otro servicio de salud público o privado. Como parte complementaria, dentro del artículo 16bis 8 se incluyó la idea de que el gobierno capitalino debería promover políticas integrales de salud sexual para prevenir los embarazos no deseados, además de crear una consejería médica y social para proporcionar a la mujer información sobre las causales excluyentes y sobre las alternativas a esa decisión, además de brindarle apoyo después de recurrir a dicha práctica.

\section{EL PUNTO MÁS ÁLGIDO DE LA DISPUTA}

El debate rebasó las fronteras del país cuando el Vaticano asumió una postura sobre el tema, violando el artículo 33 constitucional que niega a los extranjeros la posibilidad de inmiscuirse en los asuntos políticos del país. El papa Benedicto XVI se manifestó en contra de que la iniciativa prosperara en la Ciudad de M éxico y en el resto de la República. Por la trascendencia de la controversia, la Santa Sede buscó hacer uso de una estrategia que le ha dado buenos resultados en otros países, y por medio de la cual en América latina ha tratado de subordinar la acción de los estados - sobre todo aquellos encabezados por gobiernos conservadores- e incidir en asuntos de política interna. Así, en una carta enviada a la LXXXIII Asamblea General de la CEM, presentada por el secretario de Estado del Vaticano, cardenal Tarcisio Bertone, el papa manifestó su "esperanza" de que la Ley fuera rechazada: "En este tiempo pascual, con la resurrección de Cristo estamos celebrando el triunfo de la vida sobre la muerte. Este gran don nos impulsa a proteger y defender con firme decisión el derecho a la vida de todo ser humano desde el primer instante de su concepción, frente a cualquier manifestación de 
la cultura de la muerte" (Balboa, 2007b). En este mismo sentido, la CEM hizo el siguiente llamado:

A los hombres y mujeres que profesen la religión católica no deben apoyar las propuestas sociales o políticas que favorezcan acciones contra la vida como el aborto y la eutanasia [... ] es un desorden moral grave [... ]. Los obispos [... ] compartimos nuestra preocupación sobre el tema de la vida y recordamos que una obligación primaria del Estado consiste en velar y defender el derecho natural de todo ser humano a la vida y a la integridad física desde la concepción hasta la muerte. Si una ley positiva priva a una categoría de seres humanos de la protección que el ordenamiento civil les debe, el Estado niega la igualdad de todos ante la ley. Cuando el Estado no pone su poder al servicio delos derechos detodo ciudadano, y particularmente de quien es más débil, se quebrantan los fundamentos mismos del estado de derecho (Ídem).

Ante la demanda de mayores acciones en oposición a la iniciativa de ley, el cardenal Norberto Rivera prometió al papa "defender con decisión firme el derecho a la vida y avanzar en una cruzada por la Paz" (León, 2007a)..$^{13}$ Por su parte, Ios panistas, José Espina von Roerich, secretario general de ese partido y Carlos Abascal, defendieron la intervención del papa. El primero argumentó quela carta del pontífice no contravenía ninguna norma constitucional, en tanto que había sido enviada a los

\footnotetext{
${ }^{13}$ La actitud del arzobispo de Morelia, Alberto Suárez Inda, fue más radical al afirmar que: "a la I gl esia católica no le importa vulnerar el Estado laico para defender el derecho a la vida". Además, el semanario Desde la Fe, publicado por la Arquidiócesis, abrió una de sus ediciones con el artículo "¿Puede la I glesia meterse en política?", el cual fue firmado por el sacerdote Mario Ángel Flores. En el texto se planteaba que desde la reforma constitucional de 1992 cuando se reconoció la personalidad jurídica de todas las iglesias y asociaciones religiosas "se [reconoció] su capacidad de actuación pública [... ] por lo que es un hecho que [éstas] pueden desempeñar libremente sus actividades, mismas que están estipuladas en sus principios, que son del pleno conocimiento del Estado mexicano, que no se limita a actos de culto sino a todo lo que es su código doctrinal" (citado en León, 2007a).
} 
obispos mexicanos, no a la ALDF; Abascal, por su parte, planteó que la carta de Benedicto XVI no era "injerencista", que el tema de la despenalización del aborto no era un asunto del Estado laico, sino de vida; también calificó de "ignorantes y jacobinos" a los legisladores de la Asamblea que solicitaron a la SEGo que se enviara al pontífice una nota diplomática en protesta por sus declaraciones (Ramírez, 2007).

Hasta ese momento de la confrontación, el entonces subsecretario de Población, Migración y Asuntos Religiosos de la SEGOB, Florencio Salazar Adame, manifestó haber solicitado a la Arquidiócesis que moderara su discurso en torno al aborto; pero al expresar su interpretación sobre el contenido del artículo 130 constitucional, dijo: "ese precepto niega la posibilidad de que los ministros de culto se involucren activamente en la vida política básicamente en el contexto de los procesos electorales" (Pérez, 2007). Luego agregó que las opiniones de los sacerdotes y el Papa se habían hecho en un "contexto democrático", por lo que si bien el reglamento de la Ley de Asociaciones Religiosas y Culto Público contempla sanciones diversas para los ministros que vulneren la norma constitucional (desde apercibimientos hasta la cancelación del registro de la asociación en cuestión), no se les podía sancionar. En el mismo sentido que Florencio Salazar, se dio la declaración de Manuel Espino, quien en su calidad de líder de la Organización Demócrata Cristiana de América (ODCA) y ex dirigente nacional del PAN, dijo:

[... ] la despenalización del aborto es una expresión de desprecio a la democracia, cuya esencia reside en la defensa y promoción de los derechos de todos, especialmente de los más débiles [... ]. Los treinta y cinco partidos políticos pertenecientes a la ODCA refrendan su defensa del respeto irrestricto al derecho a la vida en todas sus etapas y manifestaciones [... ]. Los partidos demócratas y humanistas de América protestamos enérgicamente contra la idea de que un embrión no es un ser humano (Reséndiz, 2008). 
Es cierto que en sus primeros años de vida opositora, el PAN aceptó e incluso promovió como base de la vida republicana, la separación entre el poder de la I glesia y el del Estado (Reynoso, 1996), por lo que admitió el repliegue de las prácticas religiosas a la intimidad de la vida personal. Al fundarse, en 1939, como una institución política moderna para su tiempo, que abogaba por la necesaria construcción de una ciudadanía consciente, como sustento de un sistema político democrático, Acción Nacional se comprometió con una concepción de los individuos actuando como ciudadanos en el ámbito público y reconociéndose como creyentes en el espacio privado. No obstante, la desmedida actuación en contra de las reformas en cuestión que asumió el PAN se debe a la mutación que ha sufrido desde la segunda mitad de los años setenta, pero especialmente en las dos últimas décadas del siglo XX. El ascenso de los grupos ultra conservadores (Hernández Vicencio, 2009) en su interior ha facilitado cada vez más la adopción a pie juntillas de un discurso que desde Roma se ha desplegado en relación con el significado de la vida democrática. Para la Santa Sede debe existir una sana laicidad, que ha sido definida por Benedicto XVI como el sistema que garantiza a cada ciudadano el derecho de vivir su propia fe religiosa con libertad, incluso en el ámbito público, por lo que un gobierno verdaderamente democrático no sólo vigila que esta premisa se cumpla, sino que la promueve.

Al calor de la discusión y ante la inminente aprobación de la ley, la APM y la UNPF convocaron para el 22 de abril de 2007 a sus aliados a una nueva peregrinación "Por la Vida", que esta vez partió del Monumento a la Madre y concluyó en la Catedral Metropolitana, donde los peregrinos fueron recibidos por el cardenal Norberto Rivera (Avilés, 2007). ${ }^{14}$ En la marcha hubo representantes de alrededor de veinte organizaciones civiles afines a la UNPF y al Movimiento Somos Vida, así como militantes del PAN y del PVEM. Entre las organizaciones de la

\footnotetext{
${ }^{14}$ A la cabeza de la manifestación iba el rector de la antigua Basílica de Guadalupe, monseñor Pedro Agustín Rivera, detrás de quien caminaron las Hijas de María Inmaculada de Guadalupe, coreando consignas como las siguientes: “ $\mathrm{iEn}$ el nombre de la virgen cósmica, no pasarán!, ¡defiende a vida cueste lo que cueste!, ¡Por el asesinato de tus futuros discípulos!, ¡Por el derramamiento de sangre en toda la nación!" (véase Avilés, 2007).
} 
sociedad civil que se mostraron más activas para rechazar la ley estuvieron: Dignidad Ciudadana; Alianza por la Vida y la Familia; Tejiendo Redes; Alianza de Maestros; Familia Eucarística; Yo Influyo; Suma por la Educación; Unión de Voluntades; Caballeros de Colón; La Orden de la Cruz de Malta, y la Orden de Los Templarios. A esta nueva movilización también se integraron grupos nazi-fascistas que decidieron salir a la escena pública por considerar que la lucha por la despenalización del aborto era parte de una "conspiración judeo-masónica". En ese contingente aparecieron militantes del Partido N acional Social ista (PNS), así como integrantes de la denominada UR en México, grupo fascista no católico creado en Italia en la década de los treinta, y algunos integrantes de la denominada Guardia N acional Mexicana. Si bien estos grupos no han tenido una participación tan visible, sí han estado muy activos a través de algunas páginas de Internet, por medio de las cuales tienen contacto con sus simpatizantes y expresan sus puntos de vista sobre distintos temas (Ibíd.). ${ }^{15}$

No obstante, es muy importante destacar que a lo largo de los meses en los que transcurrió el debate, también quedó claro que entre los propios católicos había diferencias importantes. Por ejemplo, frente a la postura de los grupos católicos conservadores, se expresaron algunos sacerdotes jesuitas y dominicos, quienes distinguieron el carácter moral del aborto y su estatuto legal; así como la agrupación Católicas por el Derecho a Decidir (CDD), organización de mujeres laicistas que defienden su derecho a decidir sobre su cuerpo. Hay que decir que la reivindicación de la laicidad no corresponde únicamente a las corrientes laicistas, sino también a las confesiones religiosas minoritarias y a los grupos minoritarios dentro de la Iglesia católica, que encuentran en el

\footnotetext{
${ }^{15}$ Para las mujeres pro nazis existe la página Web Ilamada M ujer Criolla donde aparecen desplegados en contra del "aborto-asesinato" y opiniones como la siguiente: "Las mujeres (madres de nuestra raza), están siendo engañadas por mal ditas zorras lesbianas, con complejos de inferioridad que odian a los hombres [... ]. No estamos en contra de que la mujer trabaje, pero sí estamos en contra de que no cumpla con el verdadero rol quela naturaleza le dio al concebir [... ]. No vamos a permitir que unas frustradas y enemigas de la naturaleza, quieran legalizar el aborto. El aborto es una amenaza y atenta contra nuestra nación, contra la naturaleza y la vida humana [... ]", citado en s.a., Milenio Semanal, mayo 7 de 2007, pp. 6-7.
} 
Estado laico la garantía para el pleno ejercicio de su libertad. En ese contexto, este sector de católicas se ubican más cerca del denominado laicismo religioso, que cree en el uso de los valores cristianos como motor para la transformación social y el desarrollo de ciudadanos políticamente activos (Díaz-Salazar, 2007). CDD participó en distintos actos junto con diputadas del PRD y con integrantes de organizaciones como Decidir; Equidad de Género: Ciudadanía, Trabajo y Familia; Elige; Fundación Mexicana para la Planeación Familiar (MEXFAM) y la red por los Derechos Sexuales y Reproductivos en México. ${ }^{16}$ Según O maira O choa, de CDD, su participación en las manifestaciones de apoyo a la nueva ley se debía a su convicción de que "las enseñanzas morales de la Iglesia no están acordes con la realidad que viven los feligreses, por lo que deben respetar la vida personal de los católicos y el Estado laico" (Norandi, 2007).

Debido a la clara derrota que el panismo experimentó en la ALDF con la aprobación del dictamen y su inminente paso al pleno de la Asamblea, la dirigente del PAN en el Distrito Federal, Mariana Gómez del Campo (sobrina de Margarita Zavala) y las diputadas locales encabezadas por Carmen Segura, comenzaron a pensar en las acciones que llevarían a cabo en caso de que se aprobara la ley, ${ }_{1}^{17}$ por lo que solicitaron a la Comisión de Derechos Humanos del Distrito Federal (CDHDF), que - de aprobarse la ley- interpusiera una acción de inconstitucionalidad ante la SCJN. Emilio Álvarez Icaza, titular de la comisión se negó a presentar dicho recurso, pero en un hecho sin precedenteel O mbudsman de la Comisión Nacional de Derechos Humanos (CNDH), José Luis Soberanes, y el titular de la Procuraduría General

\footnotetext{
${ }^{16}$ Un libro que muestra las opiniones de distintos actores a favor de la ley es el coordinado por Lourdes Enríquez y Claudia de Anda (2008).

17 Una de las acciones fue la realización de un spot que se transmitió por televisión en cadena nacional, en el que se presentó la imagen de un juez dictando sentencia contra un feto. La SCJN interpuso una querella ante el Instituto Federal Electoral (IFE) al considerar que el mensaje transmitido por televisión era tendencioso. El IfE dio instrucciones de retirar del aire el spot y anunció que indagaría si existían las pruebas suficientes para fincar responsabilidades al PAN, por haber violado el artículo 38, párrafo 1, inciso "p", del Código Federal de Instituciones y Procedimientos Electorales (COFIPE) que regula las calumnias y difamaciones en que pueden incurrir los partid os políticos contra sus adversarios o contra las instituciones (véase Urrutia, 2007).
} 
de la República (PGR), Eduardo Medina Mora, anunciaron su disposición a atender el Ilamado de las diputadas panistas y de la alta jerarquía de la Iglesia católica.

\section{LA RESOLUCIÓN Y SUS CONSECUENCIAS}

Después de cinco meses de discusiones, el 24 de abril de 2007, el pleno de la ALDF aprobó (con cuarenta y seis votos a favor, diecinueve en contra y una abstención) ${ }^{18}$ el dictamen por el que se despenalizó el aborto entre la primera y la décima segunda semana de embarazo; además se responsabilizó al gobierno capitalino de otorgar los servicios de consejería médica y social gratuita en materia de atención a la salud sexual y reproductiva. Las reformas penales que aprobó la Asamblea modificaron cuatro artículos del Código Penal y dos de la Ley de Salud del Distrito Federal; la reforma tuvo efecto a partir del 26 abril, fecha en que fue publicada en la Gaceta O ficial del Distrito Federal. ${ }^{19} \mathrm{~A}$ partir de ese momento se abrió la posibilidad para que las instancias que lo desearan pudiesen impugnar ante la SCJN, en los siguientes 30 días.

La reacción de los obispos no se hizo esperar. Tal fue el caso de los obispos del sureste mexicano y el cardenal Rivera Carrera, quienes arremetieron contra los legisladores que votaron a favor de la reforma y amenazaron con excomulgarlos (León, 2007b). ${ }^{20} \mathrm{Al}$ respecto, el obispo de San Cristóbal de las Casas, Felipe Arizmendi, afirmó: "ganó el imperio de la muerte, el orgullo partidista, un laicismo decimonónico que pretende excluir de la política todo lo que huele a Dios [... ] los

\footnotetext{
${ }^{18}$ El diputado priísta Armando Tonatiuh González, que inicialmente había presentado una iniciativa, a última hora se abstuvo de votar ante las presiones ejercidas por los obispos católicos que mencionaron la posibilidad de la excomunión. Para aclarar su postura el diputado dijo: "soy un católico, temeroso de Dios" (véase Romero, 2007).

${ }^{19}$ Las modificaciones al Código Penal del Distrito Federal pueden verse en la siguiente dirección de Internet: http//www.df.gob.mx/leyes/normatividad.html?materia= $1 \&$ apartado $=16 \&$ ddisp $=394$.

${ }^{20}$ Al contrario de la posición de la I gl esia católica, se expresaron los líderes de la I glesia presbiteriana y la Confraternidad Nacional de Iglesias Cristianas Evangélicas (CONFRATERNICE), quienes previamente habían manifestado que - en caso de que la ley fuese aprobada- ellos la respetarían (León, 2007b).
} 
legisladores convirtieron esta batalla en una lucha por demostrar que no dependen de la I glesia católica, que no les importa el Papa, que ceder daría la impresión de lesionar el laicismo oficial" (Balboa, 2007c).

En opinión del cardenal Norberto Rivera, la única forma para resarcir el daño era el arrepentimiento sincero por parte de los diputados y funcionarios del gobierno del Distrito Federal, por lo que dijo: "será necesario confesarse para eliminar la excomunión [... ] mostrar arrepentimiento por el pecado cometido [... ] deberán cumplir la penitencia que se les imponga [... ] trabajar para echar atrás la ley criminal e inicua que aprobaron [... ] de otra forma no es posible volver al seno de la Santa Madre Iglesia [...] oremos por la conversión de los asambleístas" (Balboa, 2007c).

Por si fuera poco, el cardenal hizo un llamado a no respetar la ley aprobada:

Ninguna circunstancia, ninguna finalidad, ninguna ley en el mundo podrá jamás hacer lícito un acto que es intrínsecamente ilícito, porque es contrario a la ley de Dios, escrita en el corazón de todo hombre, reconocible por la razón misma y proclamada por la Iglesia [pido] a todas las personas de recta conciencia no hacerse responsables de este acto abominable [...] por la aplicación de esta ley podrían verse involucrados en un execrable asesinato. [La ley] socava gravemente las bases del derecho y daña la convivencia civil, en la que los derechos de todos deben ser respetados [... ] no se puede justificar el aborto pretendiendo negar el estatuto humano del embrión. El ser humano debe ser respetado y tratado como persona desde el instante de su concepción [... ] el cambio de términos legales, es decir, la definición de aborto no lo hace moralmente lícito [... ]. Recordamos al personal de salud que pueden hacer valer su derecho a la objeción de conciencia [deben] hacerse responsables de un acto que pondría en riesgo no sólo su salud física, psicológica y moral, sino también su salud espiritual y eterna, ocasionándoles más dolor del que desean vivir [...] (Muñoz, 2007). 
La idea planteada por los sacerdotes mexicanos, en el sentido de que la Iglesia excomulgaría a quienes participaran en la realización de un aborto, a los políticos que habían aprobado la ley y al jefe de Gobierno de la ciudad de México, creó roces entre la jerarquía católica mexicana y el vocero del Vaticano. La Santa Sede negó que los políticos y funcionarios involucrados fueran excomulgados de manera automática; su portavoz, Federico Lombarda, señaló - discrepando con el discurso de la APM - que la Curia Romana no había sido oficialmente informada sobre la posible excomunión de la que habían hablado los obispos mexicanos, y enfatizó que de acuerdo con el Código de Derecho Canónico, en el canon 1398 referido a los legrados, se establece la excomunión automática (latae sententiae) solamente para quienes ejercen el aborto (N otimex, 2007), es decir, para la mujer que busca abortar, los médicos y enfermeras, consejeros, etcétera, que participan directamente. En apoyo al planteamiento de monseñor Lombarda se manifestó el cardenal mexicano Javier Lozano Barragán, encargado del Dicasterio de Salud de la Santa Sede, lo que debilitó todavía más la postura de los jerarcas mexicanos que parecían desconocer la normatividad de su propia Iglesia.

Desde que las diputadas panistas manifestaron su intención de solicitar a la CNDH y a la PGR interponer una acción de inconstitucionalidad ante la SCJN, otras voces se habían venido sumando a dicha exigencia. El coordinador de la bancada panista en el Senado, Santiago Creel Miranda, Jorge Serrano Limón, de Provida, José Antonio Fernández, dirigente de los Caballeros de Colón, coincidieron en el sentido de que analizarían la posibilidad de interponer su propia controversia. Otros panistas que se sumaron a la lógica de la acción de inconstitucionalidad fueron los senadores Alejandro Zapata Perogordo, Alejandro González Alcocer ${ }^{21}$ y Ernesto Saro; algunos gobernadores como el de Jalisco, Emilio González Martínez, quien aseguró que en su estado el tema del aborto no era un asunto de salud pública, sino de

\footnotetext{
${ }^{21}$ Quien fuera gobernador de Baja Cal ifornia cuando el caso Paulina, nombre con el que se conoció a la adolescente que fue violada en 1999, y a quien el gobierno panista obstaculizó la posibilidad de abortar.
} 
derechos humanos (los del feto, por supuesto); y el gobernador de M orelos, Marco Antonio Adame Castillo quien dijo: "la aprobación de la ley aún no concluye [... ] como médico y como gobernador [mi] posición es a favor de los derechos humanos y de la vida, enfoque que [aplico] en cualquier situación de salud pública en la entidad [...]" (Pérez, et. al., 2007). Por su parte, la entonces titular de la Secretaría de Educación Pública (SEP), Josefina Vázquez Mota, se limitó a decir: "debe fortalecerse la agenda de prevención [por lo que] a partir del próximo ciclo escolar se incluirá en las escuelas públicas un libro de ética" (Ídem). Además, se adhirieron algunos diputados federales quienes anunciaron que presentarían en el pleno de la Cámara baja una iniciativa de ley de asistencia social, con la que planeaban: "constituir una red de apoyo a mujeres embarazadas, así como de cuneros públicos como receptáculo de bebés en custodia" (Ídem), un proyecto que - en su opinión- era una alternativa importante al problema del aborto.

La aprobación de la ley también desató nuevos desacuerdos entre respecto a la obligatoriedad en la prestación del servicio por parte de las instituciones de salud (González y Romero, 2007).22 Sobre el particular, el jefe de Gobierno del Distrito Federal planteó que todos los hospitales públicos y del sistema federal de salud que operan en la Ciudad de México estaban obligados por ley a prestar el servicio, y recordó que desde 2002, en las clínicas del Instituto Mexicano del Seguro Social (IMSS) y del Instituto de Seguridad y Servicios Sociales para los Trabajadores del Estado (ISSSTE) se han venido practicando abortos legales por otras causales. Por su parte, el titular de la Secretaría de Salud (ss), José Ángel Córdova Villalobos - que en un principio había mostrado una actitud más abierta sobre las modificaciones a la ley y afirmó que la dependencia a su cargo estaba dispuesta a colaborar con el Gobierno del Distrito Federal- terminó por retractarse. Córdova Villalobos dijo: "Si bien se reformó el Código Penal y la Ley de Salud locales, las instituciones de salud del gobierno federal asentadas en la capital no

${ }^{22}$ La I gl esia católica esgrimió la "objeción de conciencia", reconocida incluso en la ley de del Distrito Federal; a lo queel gobierno capitalino respondió en el sentido de que sólo el Seguro Popular podría negar el servicio médico para la interrupción de embarazo, debido a que esa práctica no formaba parte de su catálogo de servicios (González y Romero, 2007). 
están obligadas a realizar esta práctica porque dentro del marco jurídico al que nos apegamos no está contemplada esa intervención" (Ídem). A esta negativa se unió la del entonces director general del IMSS, Juan Molinar Horcasitas, quien planteó que la institución a su cargo se encontraba "incapacitada legalmente para practicar abortos" (Ídem).

La controversia por la aprobación de la ley no terminó ahí. El 24 de mayo de 2007 la PGR y la CNDH presentaron una acción de inconstitucionalidad ante la SCJN y, cuatro días después, el 28 de mayo, su demanda fue admitida. Además de lo sorprendente que resultó el hecho de que el presidente de la CNDH asumiera la disputa contra la ley, también fue reveladora la posición conservadora de su titular al argumentar esencialmente a favor de los derechos del no nacido. José Luis Soberanes dejó de lado la defensa del derecho de las mujeres a decidir sobresu sexualidad y reproducción, y pasó por alto su autoridad moral para tomar decisiones autónomas y responsables ante el dilema ético del aborto. En cambio, en su ponencia, el ministro Sergio Salvador Aguirre Anguiano argumentó que en la propia Constitución está garantizado el respeto de la vida desde la concepción hasta la muerte natural (SCJN, 2008).

El 25 de agosto de 2008 el pleno de la scjn inició la discusión pública del asunto. La Corte realizó seis audiencias en las que se escucharon 96 expositores: 48 participaron por la inconstitucionalidad de las normas impugnadas y 48 a su favor (Aranda, 2008a y 2008b). ${ }^{23}$ El pleno realizó cinco sesiones públicas donde se ventilaron diversos $\operatorname{argumentos}^{24} \mathrm{y}$, en una decisión histórica, el 27 del mismo mes, el pleno de la SCJN avaló por ocho votos a favor y tres en contra la constitucionalidad de las reformas al Código Penal y la Ley de Salud del Distrito Federal, por lo que dio por válida la despenalización del aborto voluntario hasta las doce semanas de gestación y se refren dó la obligación de las autoridades capitalinas de garantizar que la interrupción legal del

\footnotetext{
${ }^{23}$ La Corte recibió 184 solicitudes para intervenir en las audiencias, 124 por la inconstitucionalidad y 60 por la constitucionalidad; de éstas, 51 fueron de autoridades, 53 de autoridades civiles, 16 del sector académico, 21 a título personal y 43 de otros. 111 de los solicitantes fueron hombres y 73 mujeres (Aranda, 2008b).

${ }^{24}$ Respecto al debate que se dio entre distintos sectores de la sociedad, a raíz de las controversias constitucional es promovidas por la CNDH y la PGR, véase Flores (2009).
} 
embarazo se realice en forma gratuita y en condiciones médicas y sanitarias adecuadas. Diez ministros fijaron su postura con relación al proyecto de dictamen elaborado por el ministro ponente, Sergio Salvador Aguirre Anguiano, de los cuales José Ramón Cossío, Juan N. Silva M eza, O Iga Sánchez Cordero, José de Jesús Gudiño Pelayo, Sergio Valls, Fernando Franco, Genaro Góngora Pimentel y Margarita Luna Ramos, señalaron - cada uno con sus matices- que no existe en la Constitución, ni en los tratados internacionales suscritos por México, el Ilamado "derecho a la vida desde el momento de la concepción", así como tampoco la obligación de sancionar penalmente el aborto. ${ }^{25}$ Sólo el ministro presidente, Guillermo I. Ortiz Mayagoitia, y Mariano Azuela hablaron a favor del proyecto que proponía no sólo invalidar la reforma capitalina, sino también castigar con prisión, de tres meses a seis meses a la mujer que abortase de manera voluntaria.

La última reacción del panismo en 2008, se dio el 9 de octubre, cuando varios senadores de ese partido encabezados por César Angulo presentaron una iniciativa de ley para prohibir el aborto a nivel de la Constitución federal. Su argumento se centró en la idea de que era completamente falso que la libertad de la mujer quedase secuestrada en su embarazo y que el aborto la liberara. Por ello, pretendían reformar el primer párrafo del artículo primero de la Carta Magna, a fin de que se estableciera que: "En los Estados Unidos Mexicanos todo individuo desde el momento de su concepción, goce de las garantías que otorga esta Constitución, las cuales no podrán restringirse ni suspenderse sino en los casos y en las condiciones que ella misma establece". La iniciativa de los senadores panistas no llegó a ser discutida en el Senado, debido a la falta de quórum provocada por el vacío que crearon en la sesión los senadores del PRD y del PRI; sin embargo, a partir de ese momento, y en el marco del proceso electoral intermedio de 2009, comenzaron a tejerse alianzas entre el PAN y el PRI en varios estados del país, con el fin de impulsar modificaciones a las constituciones locales que lograran detener el proceso de despenalización del aborto más allá del Distrito Federal.

${ }^{25}$ Los detalles sobre el razonamiento del magistrado Góngora Pimentel en contra de la propuesta de inconstitucionalidad pueden verse en Góngora (2009). 


\section{COMENTARIOS FINALES}

La controversia por la despenalización del aborto mostró la disolución simbólica y fáctica de la línea divisoria entre el poder de la Iglesia católica y el poder del Estado. La sociedad mexicana está de nuevo enfrentada en el tema religioso como producto de la definición que los ciudadanos, el gobierno, los partidos y una diversidad de actores hacen respecto a un tema como el del aborto. La gran diferencia es que ahora, quienes habían sido proscritos del pacto que dio vida al moderno Estado mexicano, emergieron con vigor desde las principales instancias de poder. Los grupos conservadores avanzaron a lo largo del siglo pasado por distintas vías, hasta quedar ubicados en el espectro político a través de los partidos y el gobierno, y desde ahí se proponen vulnerar al Estado laico.

Los panistas asumieron al catolicismo como una religión de Estado, haciendo suyo un discurso que niega la pluralidad religiosa que hoy día crece en el país, como claro signo de la profunda transformación que a lo largo de décadas sufrió la sociedad mexicana. En pleno siglo XXI los dirigentes, diputados y funcionarios del ahora partido en el gobierno, el PAN, se atreven a negar el derecho de toda mujer a decidir sobre su cuerpo, y las tachan de criminales por pretender tomar de manera autónoma una decisión fundamental sobre su proyecto de vida. El panismo ha mostrado su cerrazón a reconocer que el tema del aborto no es un asunto de buenas conciencias, sino un problema de salud pública, que requiere de una concepción amplia sobre los derechos humanos y sobre el sentido de la política pública.

La aprobación de la ley en el Distrito Federal, que es la más avanzada de América latina, incentivó el optimismo de los grupos feministas que la consideraron un triunfo frente a la derecha; pero también, como ya se comentó, puso en alerta a los sectores conservadores de distintas entidades de la República que inmediatamente después de su aprobación en la capital del país comenzaron a movilizarse para aprobar iniciativas de ley antiaborto. La principal sorpresa en esta contraofensiva ha sido que en al gunas de esas entidades, las propuestas fueron promovidas inicialmente por los diputados del Revolucionario Institucional y, por supuesto, ampliamente apoyadas por el PAN. A raíz de los cambios 
a la ley en la Ciudad de México, para el mes de septiembre de 2009, habían sido aprobadas en el país reformas a las constituciones locales en quince estados, las cuales consagraban el respeto a la vida desde el momento de la concepción, con lo que detenían toda posibilidad de despenalización del aborto e inclusive, en algunos casos como el de Q uerétaro, lo prohibían en caso de violación. Hay que decir que, en la mayoría de los congresos, la aprobación de las modificaciones a la ley se realizó sin ningún debate entre sus promotores y las voces discordantes; por consiguiente, sellevaron a cabo votaciones en forma económica sobre propuestas que habían sido previamente acordadas por los líderes del PRI y el PAN.

Más allá del conflicto entre la Iglesia católica y el Estado, el problema del aborto y otras cuestiones como la enseñanza de la religión católica en las escuelas, la eutanasia o los matrimonios entre personas del mismo sexo, abren nuevos retos para la reflexión política, y en específico para el debate sobre los requisitos de la construcción actual de la ciudadanía, un tema en el que paradójicamente el PAN fue pionero al ponerlo en la mesa de discusión. No obstante, la actuación actual de este partido y de sus gobiernos dista mucho de mostrar la propuesta de un partido de derecha moderno que, como lo hacen otros partidos conservadores en el mundo, como el Partido Popular español, por lo menos manifieste una mayor apertura al debate sobre bases científicas y una concepción social sobre temas fundamentales de la agenda pública contemporánea, tales como el del aborto.

\section{FuENTES CONSULTADAS}

Aranda, J., (2008a), "De trascendencia nacional, validar aborto voluntario en el DF: Corte", en La Jornada, 29 de agosto, M éxico: Desarrollo de Medios (DEMOS) S. A. de c. v. Artículo en línea disponible en http://www.jornada.unam.mx/2008/08/29/ index.php?section $=$ capital $\&$ article $=041$ n1 cap. 5 de diciembre de 2008. 
(2008b), "La ruta crítica”, en La Jornada, 29 de agosto, M éxico: DEMOS S. A. de C. V. Artículo en línea disponible en http:// www.jornada. unam. $\mathrm{mx} / 2008 / 08 / 29 /$ index.php?section $=$ capital\& article $=041$ n3cap. 5 de diciembre de 2008.

Avilés, K. (2007), “En el nombre de la 'virgen cósmica', marchan las Hijas de María Inmaculada", La Jornada, 23 de abril, México: DEMOS S. A. de C. V. Artículo en línea disponible en http:// www.jornada.unam.mx/2007/04/23/index.php?section=capital $\&$ article $=045$ n1cap. 9 de diciembre de 2008.

BalboA, J. (2007a), "Convoca el Episcopado a partidos a un diálogo democrático sobre el aborto", en La Jornada, 17 de abril, México: DEMOS S. A. de C. V. Artículo en línea disponible en http://www.jornada.unam.mx/2007/04/17/index.php?section= politica\& article $=011$ n1pol. 9 de diciembre de 2008.

(2007b), "Rechaza el papa Benedicto XVI despenalización del aborto en DF", en La Jornada, 21 de abril, México: DEMOS S. A. de C. v. Artículo en línea disponible en http://www.jornada.unam.mx/ 2007/04/21/index.php?section=capital $\&$ article=031n1 cap. 9 de diciembre de 2008.

(2007c), "Siempre cargarán esta mancha, amenaza la Iglesia", La Jornada, 26 de abril, México: DEMos S. A. de C. v. Artículo en línea disponible en http://www.jornada.unam.mx/2007/04/26/ index. php?section $=$ capital $\&$ article $=048 \mathrm{n} 2$ cap. 9 de diciembre de 2008.

Blancarte, R. (2004), Entre la fe y la política, México: Grijalbo.

Bobbio N., Matteucci, N., Pasquino, G. (dirs.) (1982), Diccionario de política, 2a ed., México: Siglo XXI.

Díaz-Salazar, R. (2007), Democracia laica y religión pública, Madrid: Taurus.

Enríquez, L., De Anda, C. (coords.) (2008), Despenalización del aborto en la ciudad de M éxico. Argumentos para la reflexión, México: Programa Universitario de Estudios de Género (PUEG)-UNAM/Protegiendo la Salud de la Mujer/Grupo de Información en Reproducción Elegida (GIRE)/Coordinación de HumanidadesUNAM. 
Esmas.com (2007), nota en línea disponible en http://www.esmas.com/ noticierostelevisa/mexicano/611035.html. 9 de diciembre de 2008.

Flores, C. (2007a), "Combatirá PAN medidas para aprobar el aborto: Abascal". Artículo en línea disponibleen http://www.esmas.com/ noticierostelevisa/mexico/611511.html. 9 de diciembre de 2008.

(2007b), "Colegio de abogados católicos anuncia movilizaciones para impedir que legisladores de la Asamblea del DF legalicen el aborto". Artículo en línea disponible en http:// www.esmas.com/noticierostelevisa/mexicano/610659.html. 9 de diciembre de 2008.

FLORES, J. (2009), Foro sobre la despenalización del aborto: respuesta social frentea las controversias, M éxico: Centro de Investigaciones Interdisciplinarias en Ciencias y Humanidades (CIICH)-UNAM/ Facultad de Medicina-UNAM/Instituto de Investigaciones Filosóficas (IIF)-UNAM/La Jornada.

Góngora Pimentel, G. (2009), De quién es la vida, México: Instituto Nacional de Ciencias Penales (INACIPE).

González Ruiz, E. (2007), "El Vaticano interviene en México contra el aborto", en kaosenlared.net, 23 de marzo, artículo en línea disponible en http://www.kaosenlared.net/noticia/vaticanointerviene-mexico-contra-aborto. 9 de diciembre de 2008.

GonzÁlez, R., Romero, G. (2007), "Analiza el GDF iniciar procesos contra hospitales que no acaten ley sobre aborto", en La Jornada, 28 de abril, M éxico: Demos S. A. de c. v. Artículo en línea disponible en http://www.jornada.unam.mx/2007/04/28index.php?section= capital $\&$ article $=032$ n1cap. 9 de diciembre de 2008.

Hernández, E. (2007), "pAn, en contra del aborto". Artículo en línea disponible en http://www.esmas.com/noticierostelevisa/mexico/ 614185.html. 9 de diciembre de 2008.

Hernández Vicencio, T. (2009), Tras las huellas de la derecha. El Partido Acción N acional, 1939-2000, M éxico: Ítaca/Seminario “M éxico Contemporáneo" del Instituto Nacional de Antropología e Historia (INAH). 
Juárez, F., Singh, S., García, S. G., Díaz O lavarrieta, C. (2008), "Estimates of Induced Abortion in M exico: What's Changed Between 1990 and 2006?", en International Family Planning Perspectives, vol. 34, núm. 4, diciembre, Nueva York: Guttmacher Institute, pp. 158-168.

Lamas, M. (2009), "La despenalización del aborto en M éxico", en N ueva Sociedad, núm. 220, marzo-abril, Caracas: Fundación Friedrich Ebert, pp. 154-172.

León Zaragoza, G. (2007a), "A la I glesia católica no le importa vulnerar el Estado laico: Suárez Inda", en La Jornada, 23 de abril, México: DEMOS S. A. de C. V. Artículo en línea disponible en http:// www.jornada.unam. mx/2007/04/23/index.php?section $=$ capital $\&$ article=044n1cap. 9 de diciembre de 2008 . (2007b), "Arquidiócesis amenaza con excomulgar a diputados que aprueben la despenalización", en La Jornada, 24 de abril, México: demos S. A. de c. v. Artículo en línea disponible en http:/ /www.jornada.unam. $\mathrm{mx} / 2007 / 04 / 24 /$ index.php?section $=$ capital $\&$ article $=043 n 1$ cap. 9 de diciembre de 2008.

Llanos Samaniego, R. (2007), "Calderón debe fajarse los pantalones y defender la vida: Serrano Limón", en La Jornada, 18 de abril, México: DEMOS S. A. de C. V. Artículo en línea disponible en http://www.jornada.unam.mx/2007/04/18/index.php?section= capital $\&$ article $=045$ n1cap. 9 de diciembre de 2008.

, Romero Sánchez, G. (2007), "Derrotan intención del PAN de hacer referéndum sobre el tema", La Jornada, 18 de abril, México: demos S. A. dec. v. Artículo en línea disponible en http:/ /www.jornada.unam.mx/2007/04/18/index.php?section= capital $\&$ article $=044 \mathrm{n} 2$ cap. 9 de diciembre de 2008.

Martínez, F., Muñoz, A. E., Garduño, R., Méndez, E. (2007), "Llama la I glesia a usar 'todos los medios' para defender la vida", en La Jornada, 29 de marzo, México: DEmos S. A. de C. V. Artículo en línea disponible en http://www.jornada.unam.mx/2007/03/29/ index.php?section $=$ capital $\&$ article $=036 \mathrm{n} 2$ cap. 9 de diciembre de 2008.

s.a. (2007), en Milenio Semanal, 7 mayo, Monterrey-México D. F.: Multimedios, pp 6-7. 
Muñoz, A. E. (2007), "Llama Rivera a desobediencia de las reformas sobre aborto", en La Jornada, 30 de abril, México: DEMOS S. A. de C. V. Artículo en línea disponible en http://www.jornada. unam. $m x / 2007 / 04 / 30 /$ index. php?section =capital $\&$ article $=$ 044n1cap. 9 de diciembre de 2008.

Norandi, M. (2007), "Jóvenes convocan a caravana musical por la despenalización", en La Jornada, 23 de abril, México: DEMOS S. A. de C. V. Artículo en línea disponible en http://www.jornada. unam.mx/2007/04/23/index. php?section=capital $\&$ article $=$ 047n2cap. 9 de diciembre de 2008.

Notimex, (2007), "El Vaticano niega que Ebrard y diputados fueron excomulgados", en La Jornada, 2 de mayo, México: DEMOS S. A. de C. v. Artículo en línea disponible en http://www.jornada. unam. $\mathrm{mx} / 2007 / 05 / 02 /$ index. php?section $=$ capital $\&$ article $=$ 040n1cap. 9 de diciembre de 2008.

Parametría (2007), "México polarizado por debate sobre derecho al aborto", en Carta Paramétrica, publicación electrónica de Parametría. Investigación estratégica. Análisis de opinión y mercado. Disponible en línea en: http://www.parametria.com.mx/ DetalleEstudio.php?E=4062. 10 de febrero de 2008.

Pérez Silva, C. (2007), "Admite Gobernación excesos de la Iglesia católica en sus expresiones", en La Jornada, 24 de abril, México: DEMOS S. A. de C. V. Artículo en línea disponible en http:// www.jornada.unam. $m \times / 2007 / 04 / 24 /$ index.php?section $=$ capital $\&$ article $=042$ n2cap. 9 de diciembre de 2008.

-, Garduño, R., Méndez, E., Poy, L. (2007), "Fortalecerá la SEP la educación sexual en escuelas: titular", en La Jornada, 26 de abril, M éxico: DEMOS S. A. de C. V. Artículo en línea disponible en http://www.jornada.unam.mx/2007/04/26/index.php?section= capital $\&$ article $=049$ n2cap. 9 de diciembre de 2008.

Puente Ojea, G. (2002), El laicismo, principio indisociable de la democracia, Madrid: Europa Laica.

Ramírez, B. T. (2007), “Abascal llama 'ignorantes' y 'jacobinos' a legisladores locales", en La Jornada, 23 de abril, México: DEMOS S. A. de C. v. Artículo en línea disponible en http://www.jornada. 
unam.mx/2007/04/23/index.php?section =capital $\&$ article $=$ 046n1cap. 9 de diciembre de 2008.

Reséndiz, F. (2008), "No a la despenalización del aborto: Espino", El U niversal, 19 de septiembre, México: El Universal s. A. de c. v. Reynoso, V. (1996), "Presencia del pensamiento católico en los partidos políticos del México contemporáneo", en Roberto J. Blancarte, El pensamiento social de los católicos mexicanos, México: Fondo de Cultura Económica (FCE).

Romero, G., Llanos, R. (2007), "Es legal en el DF la interrupción del embarazo", en La Jornada, 25 de abril, México: DEMOS S. A. de c. V. Artículo en línea disponible en http://www.jornada. unam. $\mathrm{mx} / 2007 / 04 / 25 /$ index. php?section =capital $\&$ article $=$ 042n1cap. 9 de diciembre de 2008.

Sartori, G. (2003), La sociedad multiétnica, Madrid: Taurus.

Scola, A. (2007), Una nueva laicidad: Temas para una sociedad plural, Madrid: Ediciones Encuentro.

Suprema Corte de Justicia de la Nación (SCJN)-Tribunal Pleno (2008), "Acción de inconstitucionalidad 146/2007 y su acumulada 147/ 2007, relativas al decreto de reformas que despenalizan el aborto antes de las 12 semanas de gestación en el Distrito Federal", Sesión pública extraordinaria vespertina, 25 de agosto, México: SCJN , 62 pp. Documento disponible en línea en http:// www2.scjn.gob.mx/cronicas/PDF/cr_desp_aborto.pdf. 5 de diciembre de 2008.

URRUTIA, A. (2007), "Da entrada el IFE a queja de la Corte sobre spot del PAN contra el aborto", en La Jornada, 26 de abril, M éxico: DEMOS S. A. de C. V. Artículo en línea disponible en http://www. jornada.unam. $m x / 2007 / 04 / 26 /$ index. php?section=capital $\&$ article $=048$ n 1 cap. 9 de diciembre de 2008 .

Fecha de recepción: 15 de diciembre de 2008

Fecha de aprobación: 31 de julio de 2009 